\title{
Implementation of Full-Bridge Current-Fed Resonant Boost Converter using PIC microcontroller
}

\author{
S.Ajitha \\ Dept of Electrical Engineering \\ SRM University \\ Kattankulathur, Chennai
}

\author{
N.Kalaiarasi \\ Dept of Electrical Engineering \\ SRM University \\ Kattankulathur, Chennai
}

\begin{abstract}
This paper presents a current-fed full-bridge boost DC-ACDC converter with transformer isolation operating without switching power dissipation. The output voltage is regulated by dc-ac converter whose frequency changes with a constant turn-off time of transistors. The proposed converter is devoid of parasitic oscillations, as all of the parasitic capacitances and inductances are included in a resonant tank circuit. The main advantage of such systems is that they include a capacitive output filter, which is preferred in higher voltage applications. Moreover, it achieves ZCS for all active switches and zero-voltage switching (ZVS) operation for all diodes on high voltage side, which is an additional benefit. In this paper, the system operation is first explained, then a mathematical description that is useful for its design is provided, and finally, a report on the implementation of a laboratory prototype with $125 \mathrm{~W}$ power is presented.
\end{abstract}

\section{Index terms-}

Bridge, current fed, boost, Dc-Dc converter, ZVS, ZCS.

\section{INTRODUCTION}

High voltage DC-AC-DC converters with an isolation transformer are used in different types of electronic applications such as battery chargers and dischargers, uninterruptible power systems, hybrid electric vehicles. In the case of the applications where low input voltages have to be converted to high output voltages, current-fed converters are used, whereas in the case of higher power applications, full bridge boost converters are usually a good choice.

However, the design of high voltage dc-dc converters is problematic because transformer parasitic elements can change the converter behavior. The transformer leakage inductance causes undesirable voltage spikes that may damage the circuit components, and the winding capacitance may result in current spikes. A vital factor that determines the size and the cost of a converter is its operation frequency. In order to minimize the size and the cost, the frequency has to be maximized. However, higher frequencies result in the increase of transistor switching losses, and thus, the converter's effectiveness is limited. For that reason, many solutions have been proposed to minimize converter switching losses. The most popular control method of bridge converters is pulse width modulation (PWM). It utilizes a phase-shift control technique with constant frequency operation. The fixed frequency phase-shift control enables the implementation of ZCS for all converter switches.
However, the switches must provide a reverse-voltage blocking capability. Thus, they have to be constructed by means of an MOSFET in series with reverse-voltage blocking diodes. The use of the diodes increases the component count and cost, although it also causes higher conduction losses. Another solution proposed to minimize converter switching losses is a PWM boost full-bridge converter, in which the leading switches realize ZCS under wide load range, and the lagging switches realize zerovoltage switching (ZVS) under any load. Likewise in this solution, the leading switches have to be connected in series with reverse-voltage blocking diodes. In addition, a circulating current, which is a result of the introduction of an additional auxiliary inductance (connected parallel with the primary winding of the transformer), is the source of extra conduction losses.

\section{EXISTING SYSTEM DESCRIPTION}

The active clamp network serves to limit bridge switch turn-off voltage overshoot and enable the energy stored in the transformer leakage inductance to be used for zerovoltage switching. At switch turn-off that energy redistributes into the parasitic capacitance of the switches, causing a voltage overshoot capable of destroying devices. PWM phase-shift control of the bridge switches is utilized to obtain zero-current switching for two of the four bridge switches.

\section{PROPOSED SYSTEM} \section{ARCHITECTURE AND DESCRIPTION}

The proposed converter system is devoid of parasitic oscillations as all the parasitic capacitances and inductances are included in the resonant tank circuit. The characteristic feature of resonant converters is that the transformer parasites do not disturb the circuit, because they are used as resonant circuit elements. In a current fed full bridge boost converter type the overlapping conduction time of the four converter switches is kept constant and the output voltage is regulated by varying the switching frequency. The conduction time is particularly calculated to ensure ZCS operation under a wide load range. MOSFET's and body diodes are used as the converter switches without the need for any additional diodes in series. The converter transistor turn-off time is constant and is equal to the time of the parallel connected capacitor overcharge. During the ZCS switch off-time, the L-C tank circuit resonates. This traverses the voltage across the switch from zero to its peak, and back 
down again to zero. At this point the switch can be reactivated, and lossless zero voltage switching is facilitated. Therefore the switch transition losses go to zero regardless of operating frequency and input voltage. This could result in significant savings in power and improvement in efficiency. This feature of the converter makes it suitable for high frequency and high voltage converter design.

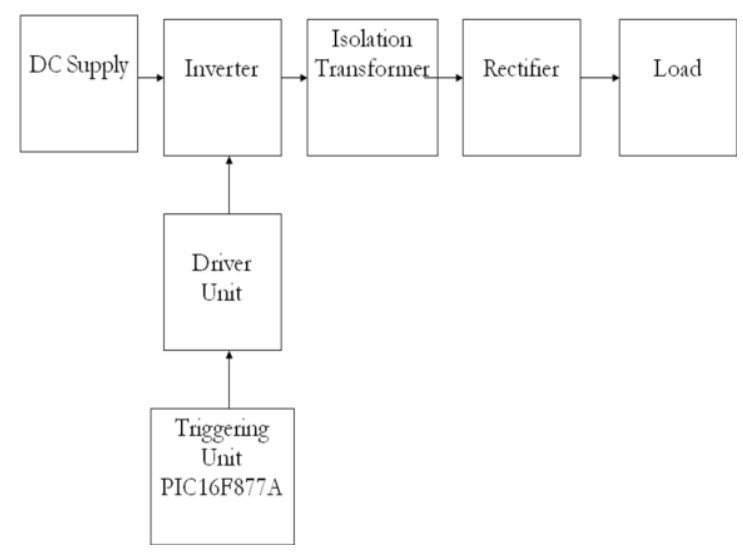

Figure.1: Block Diagram of proposed converter using PIC microcontroller

In fig.1 DC supply is given to an Inverter. The Inverter converts the DC power into AC power. The DC input voltage is converted to $\mathrm{AC}$ in order to increase the efficiency of the converter. The boosting operation is done in the Inverter circuit, which is also a boost converter. Each Mosfet acts as a switch without any switching losses and facilitates the operation of the converter. Now the boosted voltage is further passed through an isolation transformer to isolate output from the input variations if any and also the input from the load variations. The isolation transformer is connected to the rectifier circuit on the other half, where the AC voltage is converted to the DC output voltage.

PIC (16F877A) microcontroller is used as a triggering unit to generate pulses to the power switches of the Inverter. Optocoupler and a push pull amplifier are used as a driver unit to isolate and amplify the output of the microcontroller. The proposed converter scheme is shown in figure. 2. The Circuit consists of two parts one is the inverter and other is the rectifier both separated from each other by an isolation transformer. Dc converters are used in conjunction with an inductor (Lin) to generate a dc current source for current source inverter. The inverter converts the low input dc voltage into high power ac output voltage. The output of dc converter with resistive load is discontinuous and contains ripples. The ripple content in the dc output can be reduced by using capacitive filter
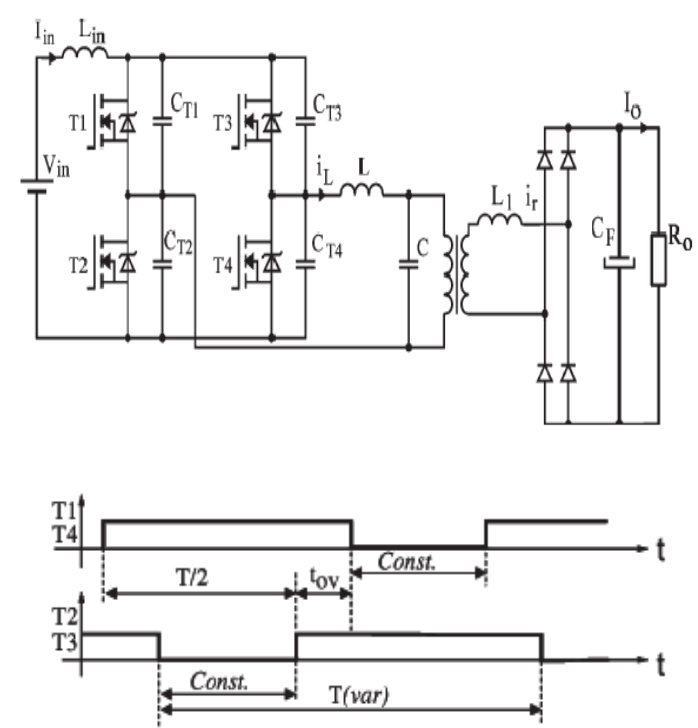

Figure.2 Proposed converter circuit a) Main circuit

\section{b) Control pulse waveform}

The inductance $L_{l}$ represents the transformer leakage inductance, the capacitance $C$ includes the transformer parasitic capacitance, and the capacitances $C_{T}$ include the transistor parasitic capacitances. The transistor control pulse waveforms are shown in the figure.

The converter is controlled by varying the switching frequency $f=1 / T$, while simultaneously keeping a constant break between the pulses. Thus, the transistor pulse overlap $t_{\mathrm{ov}}$ gradually decreases while the switching frequency increases. The maximal output voltage (power) is achieved with the minimal switching frequency, which is marked as nominal, i.e., $f n$. For this frequency, the converter operates in the optimal operation point while its transistors are switched at zero-current conditions. During the constant break between the control pulses, two transistors and two capacitors alternatively conduct T1T4CT3CT2 or T2T3CT1CT4. Because of the system symmetry, each transistor and each capacitor conducts, as in the previous subinterval, half values of the input and output current. The main task of the system design is the calculation of the transistor pulse overlap $t_{\mathrm{on}}$ and the constant break between the control pulses in accordance with the resonant circuit element parameters, i.e., $C, L$, and $C_{T}$, and the load resistance for the assumed value of the nominal switching frequency, in order to achieve the converter optimal operation point. 


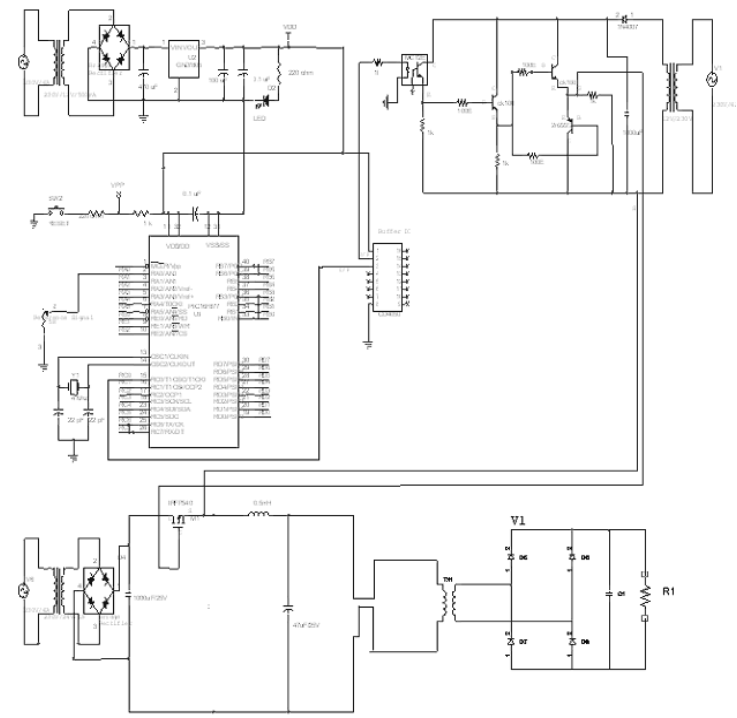

Figure 4: Hardware circuit diagram

\section{HARDWARE CIRCUIT DESCRIPTION}

\subsection{Power supply circuit}

This circuit is required to supply power to the microcontroller. In this, $230 \mathrm{~V}$ AC is supplied externally. This voltage is then reduced to $9 \mathrm{~V}$ by using a step down transformer. A bridge rectifier is used to convert AC into DC. A half wave rectifier is not used here because it cannot transfer high power Capacitors $\mathrm{C} 1$ and $\mathrm{C} 2$ are filter capacitors. They filter the ripples produced when $\mathrm{AC}$ is converted into DC by the rectifier.

A voltage regulator has been used to regulate the voltage. Its function is to provide the microcontroller with appropriate supply voltage. In this case it converts the $9 \mathrm{~V}$ coming from bridge rectifier into $5 \mathrm{~V}$. Capacitor $\mathrm{C} 3$ is a decoupling capacitor.

\subsection{Driver Circuit}

Since the output of Microcontroller is $5 \mathrm{~V}$ and the voltage required to trigger each MOSFET is $9-12 \mathrm{~V}$, the output of microcontroller is needed to be amplified. The driving circuit is used for that purpose. Here, the opto-Cupler is used as an isolator. It isolates the microcontroller from the MOSFETs. It is required because microcontroller and MOSFETs cannot be connected directly since both works at different voltage levels.

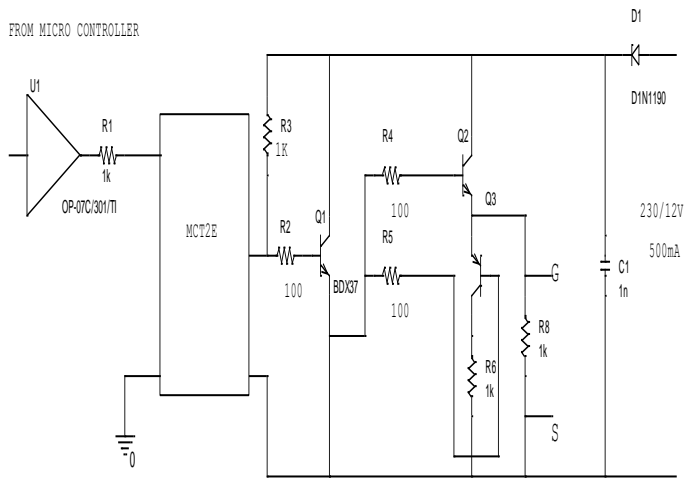

Figure 5: Driver Unit

\subsection{Inverter Circuit}

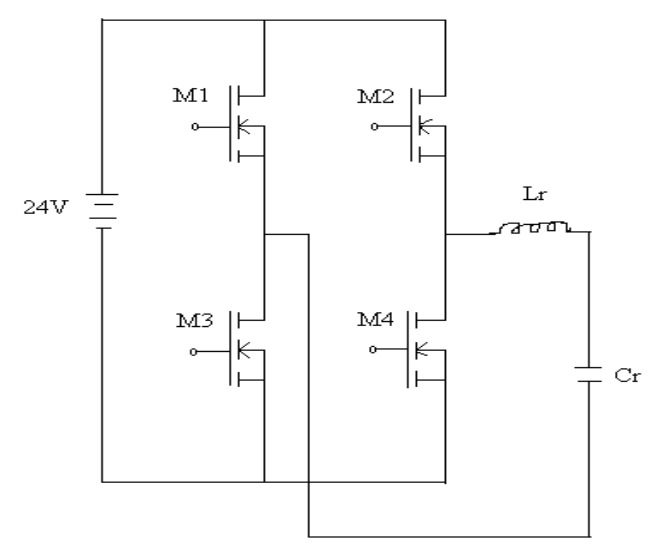

Figure 6: Inverter

A boost converter shown in figure.6 is a power converter with an output $\mathrm{AC}$ voltage greater than its input DC voltage. It is a class of switched mode power supply (SMPS) containing at least two semiconductor switches (a diode and a transistor) and at least one energy storage element. Filters made of capacitors (sometimes in combination with inductors) are normally added to the output of the converter to reduce output voltage ripple and increase the efficiency.

\section{DESIGN EXAMPLE AND SIMULATION RESULTS}

Input voltage, $\mathrm{Vin}=500 \mathrm{~V}$

Switching frequency, $\mathrm{F}_{\mathrm{N}=1000 \mathrm{~Hz}}$

Transformer voltage ratio, $\mathrm{K}_{\mathrm{t}}=1$

Leakage inductance, $\mathrm{L}_{1}=50 \mu \mathrm{H}$

$\mathrm{R}_{\mathrm{L}}=45 \mathrm{~K} \Omega \quad \mathrm{C}_{\mathrm{r}}=1000 \mathrm{nF}$

$\mathrm{L}_{\mathrm{r}}=16.5 \mu \mathrm{H} \quad \mathrm{C}=500 \mu \mathrm{F}$ 


\subsection{Simulation Design Calculation}

Resonant frequency $=1000 \mathrm{~Hz}$

Input voltage $=500 \mathrm{~V}$

Formula : $\mathrm{F}_{\mathrm{r}}=1 / 2 \pi \sqrt{ } \mathrm{L}_{\mathrm{r}} \mathrm{C}_{\mathrm{r}}$

$1000=1 / 2 \pi \sqrt{ } \mathrm{L}_{\mathrm{r}} \mathrm{C}_{\mathrm{r}}$

$$
\mathrm{L}_{\mathrm{r}} \mathrm{C}_{\mathrm{r}}=2.533 * 10^{\wedge-8}
$$

Let us assume $\mathrm{C}_{\mathrm{r}}=1000 \mathrm{nF}$. Then by calculation the $\mathrm{L}_{\mathrm{r}}$ value is designed as $16.5 \mu \mathrm{H}$

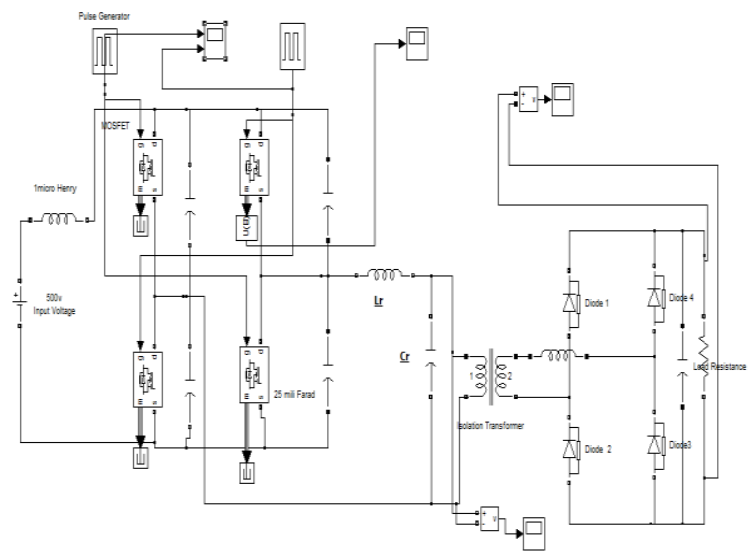

Figure :7 Simulated Circuit

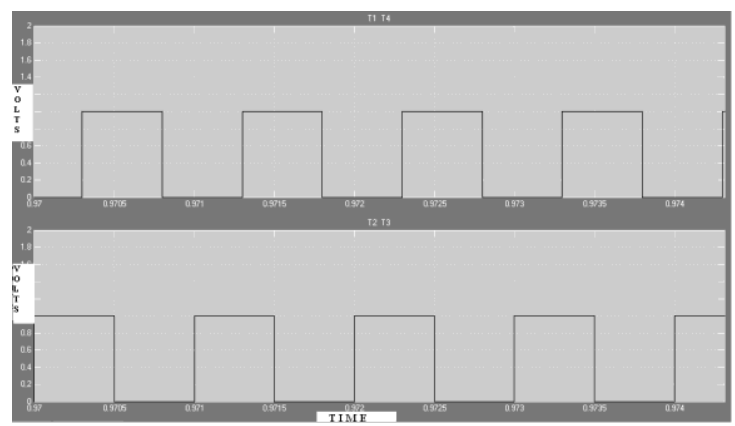

Figure10: Transistor control pulse waveform

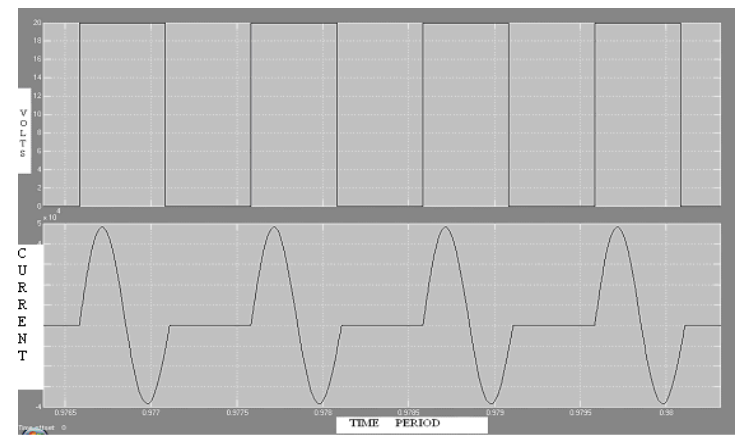

Figure 11: Zero current switching waveform

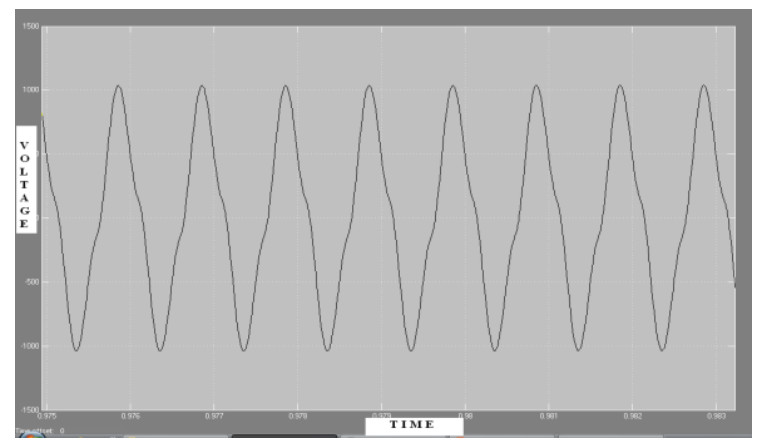

Figure.12: Inverter boost output waveform

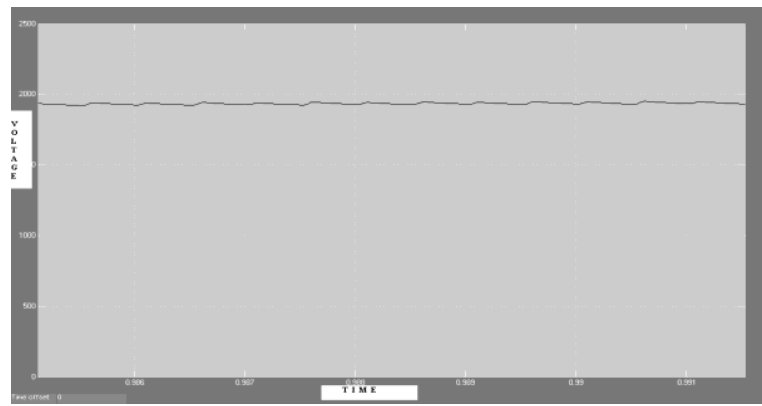

Figure.13: DC output waveform

\section{PROTOTYPE HARDWARE CIRCUIT}

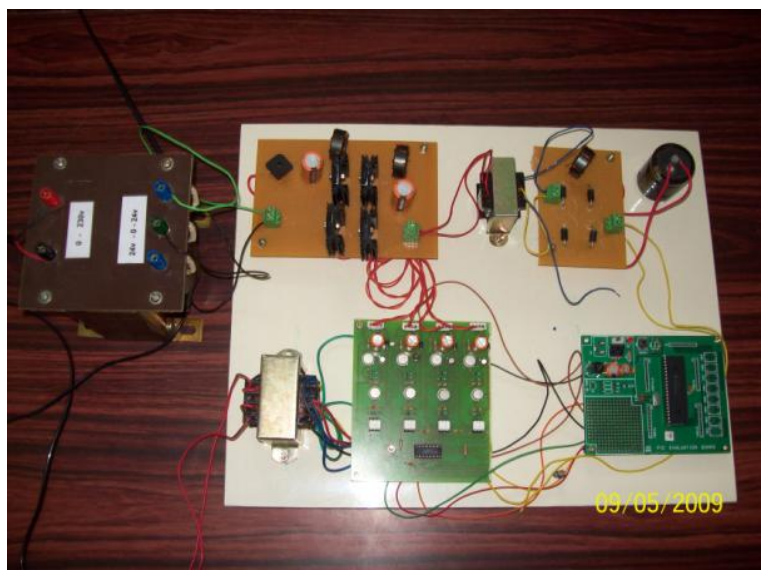

Figure.14: Prototype hardware

\subsection{Prototype Design Calculation}

Resonant frequency $=220 \mathrm{~Hz}$ Input voltage $=24 \mathrm{~V}$

Formula : $\mathrm{F}_{\mathrm{r}}=1 / 2 \pi \sqrt{\mathrm{L}_{\mathrm{r}} \mathrm{C}_{\mathrm{r}}}$ $220=1 / 2 \pi \sqrt{ } \mathrm{L}_{\mathrm{r}} \mathrm{C}_{\mathrm{r}}$ $\mathrm{L}_{\mathrm{r}} \mathrm{C}_{\mathrm{r}}=52.388 * 10^{\wedge-8}$ Let us assume $\mathrm{C}_{\mathrm{r}}=1000 \mu \mathrm{F}$

By calculation the $L_{r}$ value is designed as $250 \mu \mathrm{H}$ 


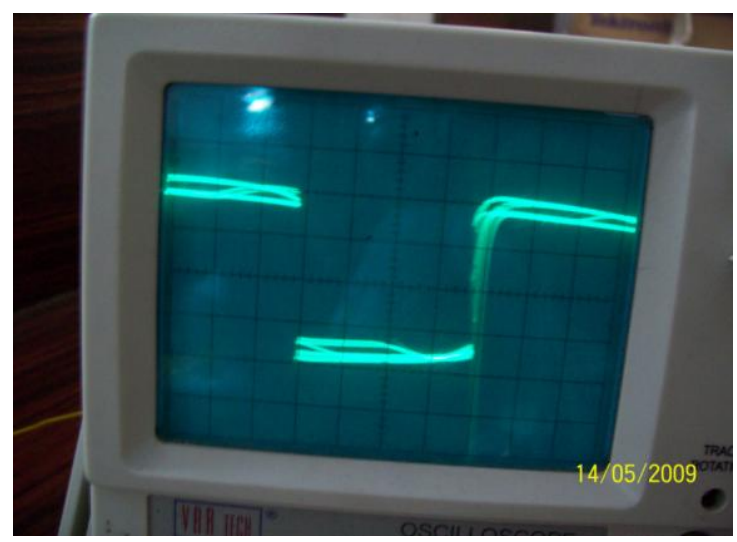

Figure.15: Experimental transistor control pulse

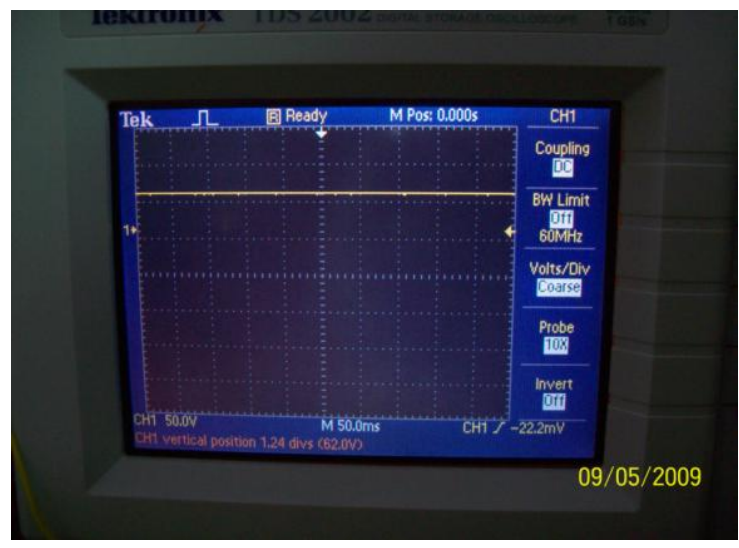

Figure.16: Experimental output voltage

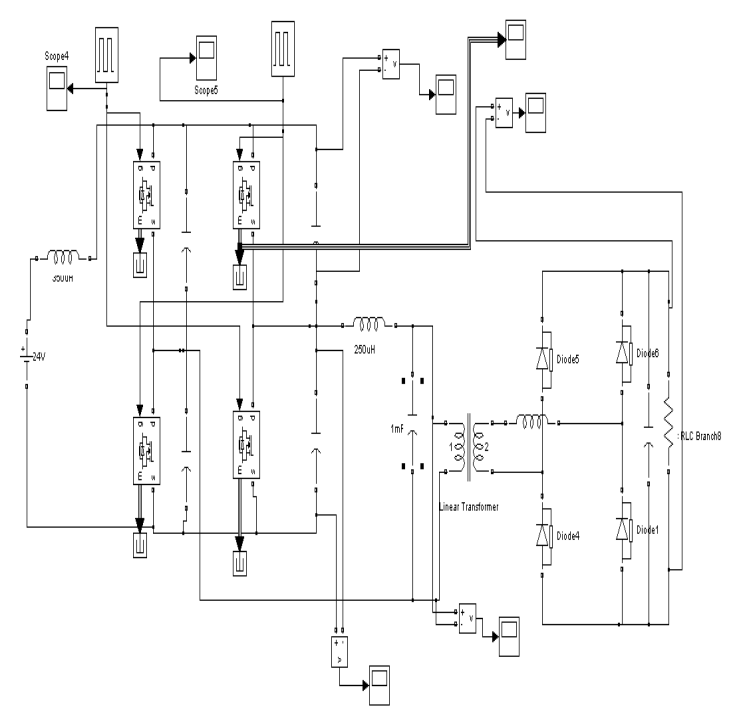

Figure.17: MATLAB simulation for the hardware prototype

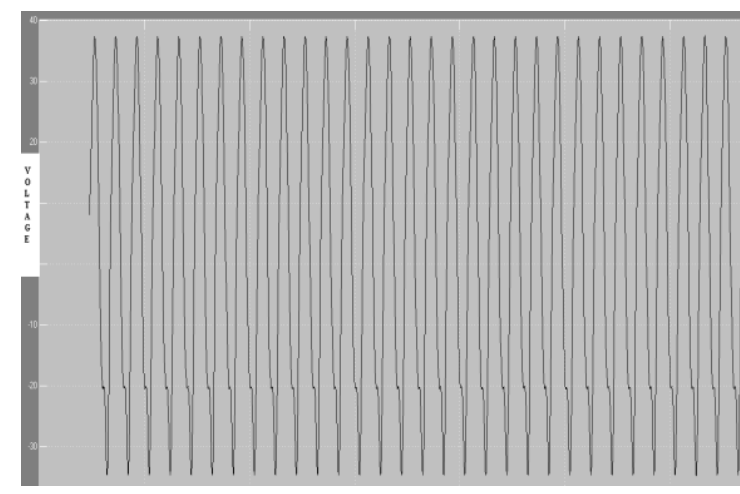

Figure.18: Simulated output of the Inverter for the prototype model

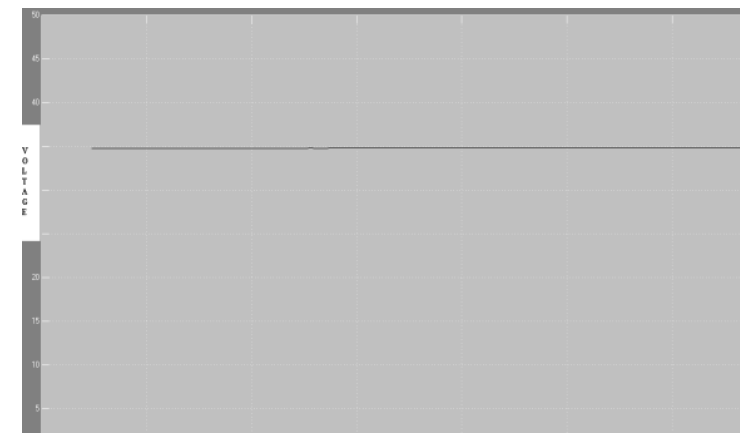

Figure.19: Simulated DC output voltage for the prototype model

Table.1Comparison between Simulation and Hardware

Results

\begin{tabular}{|c|c|c|}
\hline Parameters & Simulation & $\begin{array}{c}\text { Hardware } \\
\text { Results }\end{array}$ \\
\hline Input Voltage & $24 \mathrm{~V}$ & $24 \mathrm{~V}$ \\
\hline Input Inductance & $350 \mu \mathrm{H}$ & $350 \mu \mathrm{H}$ \\
\hline $\begin{array}{c}\text { Operating } \\
\text { frequency }\end{array}$ & $220 \mathrm{~Hz}$ & $220 \mathrm{~Hz}$ \\
\hline $\begin{array}{c}\text { Resonant } \\
\text { Inductance }\end{array}$ & $250 \mu \mathrm{H}$ & $250 \mu \mathrm{H}$ \\
\hline Resonant \\
capacitance
\end{tabular}




\section{CONCLUSION}

In this paper current-fed full-bridge dc-ac-dc converter system with transformer isolation has been proposed. A simple design procedure has been illustrated using design example. Detailed matlab simulation results have been presented to evaluate the performance of the converter. The system hardware is successfully implemented and tested in the laboratory. The simulated and experimental values have been compared and they show very less deviation. So a dcac-dc converter can be used for high power application which gives constant dc output voltage with fewer losses. The main features of the proposed converter are as follows

1) The primary benefit of using a Full-Bridge dc-dc converter is its power handling capabilities and stability.

2) The ac-dc rectifier diodes operate in discontinuous range with zero voltage switching so their switching power dissipations are also minimized.

3) All the parasitic capacitances and inductances are included in the resonant circuit, so the system does not generate parasitic oscillations and is devoid of uncontrolled voltage and current spikes.

\section{REFERENCES}

[1] R. Y. Chen, R. L. Lin, T. I. Liang, I. F. Chen, and K.C.Tseng,"Current fed full-bridge boost converter with zero current switching for high voltage applications," in Conf. Rec. IAS Annu. Meeting, 2005, vol. 3, pp. 2000-2006.

[2] C. Iannello, S. Luo, and I. Batarseh, "Full bridge ZCS PWM converter for high-voltage high-power applications," IEEE Trans. Aerosp. Electron.Syst., vol. 38, no. 2, pp. 515-526, Apr. 2002.

[3] L. Zhou and X. Ruan, "A zero-current and zerovoltage-switching PWM boost full-bridge converter," in Proc. IEEE PESC Conf., 2003, vol. 2, pp. 957-962.
[4] R. Watson and F. C. Lee, "A soft-switched, fullbridge boost converter employing an active-clamp circuit," in Proc. IEEE PESC Conf., 1996, pp. 1948-1954.

[5] K. Wang, L. Zhu, H. Odendaal, J. Lai, and F. C. Lee, "Design, implementation, and experimental results of bi-directional full-bridge DC/DC converter with unified soft-switching scheme and soft-starting capability"

[6] Belaguli and A. K. S. Bhat, "Operation of the $L C C$ type parallel resonant converter as a low harmonic rectifier," IEEE Trans. Ind. Electron., vol. 46, no. 2, pp. 288-299, Apr. 1999

[7] Garcia, V., et al. "An optimized dc-to-dc converter topology for high-voltage pulse-load applications". (1994)

[8] Weinberg, A. H., and Schreuders, J. "A high-power high- voltage $\mathrm{dc}-\mathrm{dc}$ converter for space applications".IEEE Transactions on Power Electronics (1986)

[9] Hino, H., et al "Resonant PWM inverter linked dc-dc converter using parasitic impedance of highvoltage transformer and its applications to X-ray generator". . (1988)

[10]Kim, Y. J., et al. "Comparative performance evaluations of high-voltage transformer parasitic parameter resonant inverter-linked high-power dcdc converter with phase-shifted PWM scheme. . (1995).

[11] J.A.sabate, V.Vlatkovuc, R.B.Ridely, FC.Lee and B.L.Cho "design consideration for high voltage high power full bridge zero voltage switching PWM converters" in proc. Applied power electroics conf. and exposition (APEC '90) (1990)

[12] W.Chen, F.C.Lee, M.M.Jovanovic, J.ASabate, “ A comparative study of class of full bridge zerovoltage-switched PWM converters," in proc. IEEE Applied Power Electronics Conf., (1995) 